\title{
Dioleoylphosphoethanolamine Retains Cell Surface GLUT4 by Inhibiting PKC $\alpha$-Driven Internalization
}

\author{
Tomoyuki Nishizaki \\ Innovative Bioinformation Research Organization, Kobe, Japan
}

\section{Key Words}

Dioleoylphosphatidylethanolamine - GLUT4 - PKC $\alpha$ - Endocytic internalization - Glucose uptake

\begin{abstract}
Background/Aims: Phosphatidylethanolamine, a component of the plasma membrane, regulates diverse cellular processes. The present study investigated the role of 1,2-dioleoylsn-glycero-3-phosphoethanolamine (DOPE) in the trafficking of the glucose transporter GLUT4 and the glucose homeostasis. Methods: Monitoring of GLUT4 trafficking, GLUT4 internalization assay, and glucose uptake assay were carried out using differentiated 3T3-L1GLUT4myc adipocytes. Akt1/2 and PKC isozymes were knocked-down by transfecting each siRNA. Cell-free PKC assay and in situ PKC $\alpha$ assay with a FRET probe were carried out. Oral glucose tolerance test (OGTT) was performed using BKS.Cg- $+L e p^{\mathrm{db}} /+L e b^{\mathrm{db}} / \mathrm{Jcl}$ mice, an animal model of type 2 diabetes mellitus (DM). Results: DOPE increased cell surface localization of the glucose transporter GLUT4 in differentiated 3T3-L1-GLUT4myc adipocytes, regardless of Akt activation. Likewise, PKC $\alpha$ deficiency increased cell surface localization of GLUT4, that occludes the effect of DOPE. DOPE clearly suppressed phorbol 12-myristate 13-acetate-induced PKC $\alpha$ activation in the cell-free and in situ PKC assay. DOPE and PKC $\alpha$ deficiency cancelled endocytic internalization of GLUT4 localized on the plasma membrane after insulin stimulation. DOPE significantly enhanced glucose uptake into cells. A similar effect was obtained by knockingdown PKC $\alpha$, that occludes the effect of DOPE. In OGTT, oral administration with DOPE effectively restricted an increase in the blood glucose levels after glucose loading in type 2 DM model mice. Conclusion: The results of the present study show that DOPE retains cell surface GLUT4 by suppressing PKC $\alpha$-driven endocytic internalization of GLUT4, to enhance glucose uptake into cells and restrict an increase in the blood glucose levels after glucose loading in type 2 DM.

(C) 2018 The Author(s)

Published by S. Karger AG, Basel
\end{abstract}

\section{Introduction}

The glucose transporter GLUT4, which is abundantly present in skeletal muscle cells and adipocytes, plays a central role in the regulation of glucose homeostasis [1]. When activated 
by insulin, the receptor tyrosine kinase (RTK) insulin receptor phosphorylates its own receptor and insulin receptor substrate 1 (IRS-1), to recruit and activate phosphatidylinositol 3 kinase (PI3K). Activated PI3K produces phosphatidylinositol 3, 4,5-triphosphate [PI (3, $4,5) \mathrm{P}_{3}$ ] by phosphorylating phosphatidylinositol 4, 5-bisphosphate $\left[\mathrm{PI}(4,5) \mathrm{P}_{2}\right]$, and in turn, $\mathrm{PI}(3,4,5) \mathrm{P}_{3}$ binds to and activates 3-phosphoinositide-dependent protein kinase 1 (PDK1). PI3K and/or PDK1 activate Akt by phosphorylating at the threonine and serine residues $[2,3]$, to promote vesicular transport of GLUT4 towards the cell surface and exocytosis of GLUT4. Then, GLUT4 on the plasma membrane is internalized by clathrin-mediated and cholesterol-dependent endocytosis. ADP-ribosylation factor (Arf), a small G protein, recruits the effector AP-1 adaptor protein, which coordinates packaging of GLUT4 into endocytic vesicles, induces GLUT4 internalization into the cytosol [4].

Phosphatidylethanolamine (PE) is a component of the lipid bilayer in the plasma membrane as well as phosphatidylcholine, phosphatidylinositol, and phosphatidylserine. PE is shown to regulate membrane fusion, cell cycle, autophagy, apoptosis, cognitive function, and glucose homeostasis [5-10]. We have earlier found that the PE derivative 1, 2-O-bis-[8- $\{2-(2-$ pentyl-cyclopropylmethyl)-cyclopropyl\}-octanoyl]-sn-glycero-3-phosphatidylethanolamine (diDCP-LA-PE) is capable of mimicking intracellular insulin signaling [11]. This prompted assessing the effects of natural PEs on GLUT4 trafficking and glucose homeostasis. I show here that of examined PEs 1, 2-dioleoyl-sn-glycero-3-phosphoethanolamine (DOPE), with oleic acid (OA) at the $\alpha$ and $\beta$ position, restrains GLUT4 endocytic neutralization by suppressing PKC $\alpha$ activation, to retain cell surface GLUT 4, thereby enhancing glucose uptake into cells and lowering the blood glucose concentrations in the whole body.

\section{Materials and Methods}

\section{Animal care}

All experimental protocols were approved by Hyogo College of Medicine (the author's previous laboratory). All procedures using animals have been approved by the Animal Care and Use Committee at Hyogo College of Medicine and were carried out in compliance with the National Institutes of Health Guide for the Care and Use of Laboratory Animals.

\section{Cell culture}

3T3-L1-GLUT4myc fibroblast cells, expressing GLUT4myc that is constructed by inserting a human c-MYC epitope (14 amino acids) into the first ectodomain of GLUT4, were kindly provided by Prof. Ebina (University of Tokushima, Japan). Cells were cultured and differentiated into adipocytes (3T3-L1-GLUT4myc adipocytes) by the method as described previously [12]. Whether fibroblasts actually differentiate into adipocytes was confirmed with the Oil-Red 0 staining.

\section{Lipid preparation}

DOPE, 1, 2-diarachidonoyl-sn-glycero-3-phosphoethanolamine (DAPE), 1, 2-dilinoleoyl-sn-glycero3-phosphoethanolamine (DLPE), and 1, 2-dipalmitoleoyl-sn-glycero-3-phosphoethanolamine (DPPE), OA, linoleic acid (LA), linolenic acid (LnA), and stearic acid (SA) were purchased from Avanti Polar Lipids, Inc. (Alabaster, AL, USA). For cell experiments, PEs and free fatty acids (FFAs) were dissolved with polyethylene glycol (PEG) and stocked at high concentrations. At the time of experiments, stocked PEs and FFAs were diluted more than 1, 000 times with Krebs-Ringer-HEPES buffer containing $0.2 \%$ (w/v) bovine serum albumin (BSA) supplemented with $10 \mathrm{mM}$ glucose and applied to cells after formation of micelles by sonication. For animal experiments, PEs, which were dissolved with PEG to the dose of use (final volume, $0.1 \mathrm{~mL}$ ), were orally administered using a feeding needle. For cell-free PKC assay, stocked DOPE was diluted more than 1, 000 times with BSA-free medium and used after formation of micelles by sonication.

Cell surface GLUT4 localization

Cell surface GLUT4 localization were monitored by the method previously described [12]. Briefly, cells were homogenized and separated into the cytosolic and plasma membrane fractions. Whether the 


\section{Cellular Physiology Cell Physiol Biochem 2018;46:1985-1998

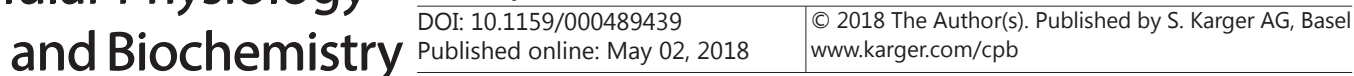

Nishizaki: Inhibition of PKC $\alpha$-Driven GLUT4 Internalization

cytosolic and plasma membrane components were successfully separated was confirmed in the Western blot analysis using antibodies against the cytosolic marker lactate dehydrogenase (LDH) and the plasma membrane marker cadherin. Then, Western blotting was carried out in each fraction using an antibody against c-myc (Merck Millipore, Darmstadt, Germany). Immunoreactivity was detected with an ECL kit and visualized using a chemiluminescence detection system. Signal density was measured with an ImageQuant software (GE Healthcare, Buckinghamshire, UK).

\section{GLUT4 internalization assay}

Differentiated 3T3-L1-GLUT4myc adipocytes were stimulated with $100 \mathrm{nM}$ insulin for $30 \mathrm{~min}$ at $37^{\circ} \mathrm{C}$ after 3-h serum starvation. Then, cells were washed with ice-cold Krebs-Ringer-HEPES buffer three times and incubated in Krebs-Ringer-HEPES buffer containing $0.2 \%$ (w/v) BSA and $10 \mathrm{mM}$ glucose for $120 \mathrm{~min}$ at $37^{\circ} \mathrm{C}$, and Western blotting was performed in the cytosolic and plasma membrane fractions.

\section{Glucose uptake assay}

Glucose uptake assay was carried out by the method previously described [12]. Briefly, extracellular glucose was labeled with $p$-aminobenzoic ethyl ester, followed by high performance liquid chromatography (HPLC) analysis. Glucose uptake was determined by subtracting the extracellular glucose concentration from the initial extracellular glucose concentration $(10 \mathrm{mM})$. It has been confirmed that insulin (100 nM) significantly increased glucose uptake into 3T3-L1- GLUT4myc adipocytes in a treatment time (20-120 min)-dependent manner [12]. To see the effect of DOPE on glucose uptake most definitely, the incubation time of PEs including DOPE in the present glucose uptake assay was set for $120 \mathrm{~min}$.

\section{Construction and transfection of small interfering RNA (siRNA)}

The siRNA to silence the Akt1/2-targeted gene (Akt1/2 siRNA), the PKC $\gamma$-targeted gene (PKC $\gamma$ siRNA),

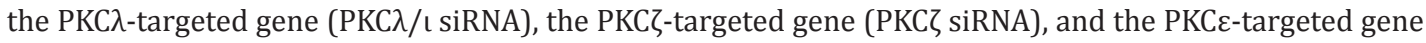
(PKC $\varepsilon$ siRNA) were obtained from Santa Cruz Biotechnology, Inc. (Santa Cruz, CA, USA). The siRNAs to silence the PKC $\alpha$-targeted gene (PKC $\alpha$ siRNA) and the negative control (NC) siRNA were obtained from Ambion (Carlsbad, CA, USA). The sequences of siRNAs used were 5'-GAACGUGCAUGAGGUGAAAtt-3' and 5'-UUUCACCUCAUGCACGUUCtt-3' for PKC $\alpha$; 5'-ACAAGUUACUGAACCAGGAtt-3' and 5'-UCCUGGUUCAGUAACUUGUac-3' for PKC $\gamma$; 5'-GGACCUCUGUGAGGAAGUGtt-3' and 5'-CACUUCCUCACAGAGGUCCtt-3' for PKC 3 ; and 5'-GCACUUGCGUUGUCCACAAtt-3' and 5'-UUGUGGACAACGCAAGUGCaa-3' for PKC $\varepsilon$. The sequence of PKC $\lambda / \mathrm{l}$ siRNA was not provided. NC siRNA had the scrambled sequence, the same GC content, and nucleic acid composition. siRNAs were transfected into cells using a Lipofectamine reagent (Invitrogen, Carlsbad, CA, USA). Cells were used for experiments 48 $\mathrm{h}$ after transfection. Knock-down of the relevant proteins was confirmed in the Western blot analysis (Fig. $1 \mathrm{~A}-\mathrm{F})$.

\section{In situ Akt assay}

Western blotting was performed using antibodies against phospho-Thr308/309-Akt1/2 (pT308/309), phospho-Ser473/474-Akt1/2 (pS473/474), or Akt1/2 (Cell Signaling Technology, Inc., Danvers, MA, USA).

\section{Cell-free PKC assay}

PKC activity in the cell-free systems was quantified by the method previously described [11]. Briefly, synthetic PKC substrate peptide $(10 \mu \mathrm{M})$ was reacted with novel PKC isozymes such as PKC $\delta$ and $-\varepsilon$ in $\mathrm{Ca}^{2+}$-free medium and the other PKC isozymes in $\mathrm{C}^{2+}$-containing medium. Then, unphosphorylated and phosphorylated PKC substrate peptides were quantified in the reversed phase HPLC analysis. Production of phosphorylated PKC substrate peptide per $1 \mathrm{~min}$ (pmol/min) was used as an index of PKC activity.

\section{In situ PKC $\alpha$ assay}

PKC $\alpha$ was monitored with the föerster resonance energy transfer (FRET) system by the method described previously [13]. Briefly, the vector for FRET probe with CFP and YFP at the N- and C-terminal ends of PKC $\alpha$, respectively, was constructed, and transfected into differentiated 3T3-L1 adipocytes using a Lipofectamine LTX-PLUS (Invitrogen, Carlsbad, CA, USA). Forty-eight hours later FRET monitoring was carried out with a Zeiss LSM510 META inverted microscope (Oberkochen, Germany). The CFP and YFT 
Fig. 1. Knocking-down of Akt1/2 and PKC isozymes. Differentiated 3T3-L1-GLUT4myc adipocytes were transfected with siRNAs for NC, Akt, and PKC isozymes as indicated, and $48 \mathrm{~h}$ after transfection Western blotting was carried out using antibodies against Akt1/2, each PKC isozyme, and $\beta$-actin. The signal intensity for each protein was normalized by that for $\beta$-actin. In the graphs, each column represents the mean ( \pm SEM) normalized expression levels for each protein $(\mathrm{n}=4$ independent experiments). $\mathrm{P}$ value, unpaired t-test.

fluorescent signals were detected at an absorbance of 474 and $506 \mathrm{~nm}$, respectively, using an excitation light of $458 \mathrm{~nm}$. The FRET ratio (YFP signal intensity/ CFP signal intensity) was calculated using an ImageJ software (National Institutes of Health, USA).

Oral glucose tolerance test (OGTT)

BKS.Cg- + Lep $^{\mathrm{db}} /+$ Leb $^{\mathrm{db}} / \mathrm{Jcl}(\mathrm{db} / \mathrm{db})$ mice (female, 8 weeks), an animal model of type 2 diabetes mellitus (DM), were purchased from CLEA Japan (Tokyo, Japan). OGTT was carried out in mice fasted for $12 \mathrm{~h}$. DOPE was orally administered $30 \mathrm{~min}$ prior to loading glucose $(2 \mathrm{~g} / \mathrm{kg}$ body weight) using a feeding needle. After collection of blood $(10 \mu \mathrm{L})$ from the tail vein, the

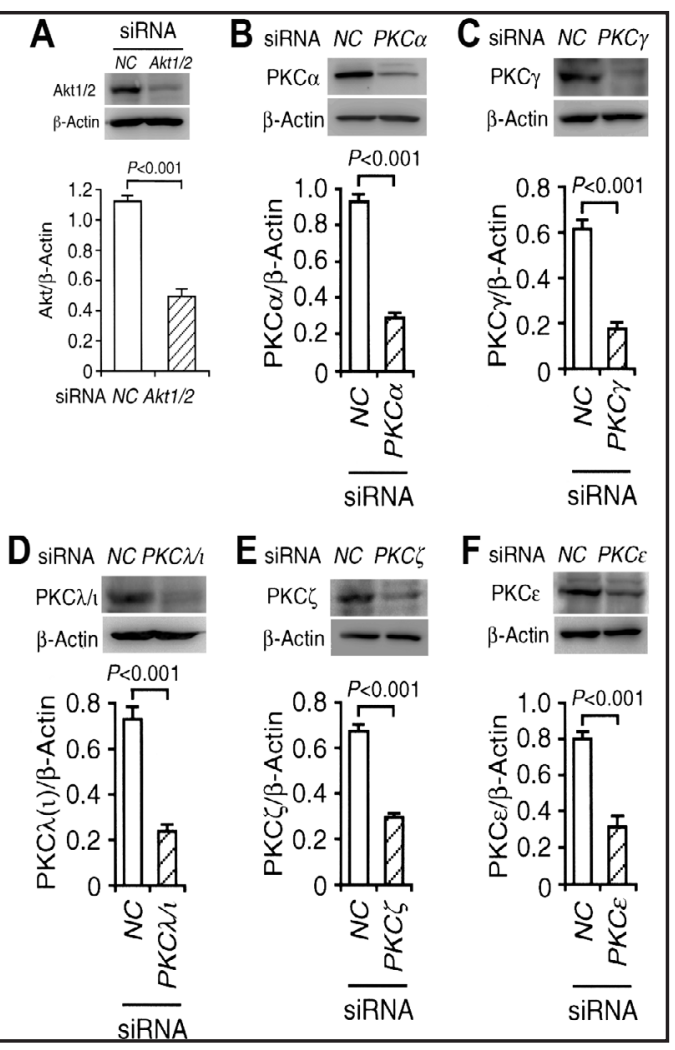
serum was prepared from collected blood, and the serum glucose levels were measured by the method previously described [11].

In the OGTT using human type $2 \mathrm{DM}$ patients, glucose $(75 \mathrm{mg})$ and lecithin containing DOPE (approximately $6 \mathrm{mg}$ ) were simultaneously taken after a 12-h fast, and the blood glucose levels were measured using a blood glucose meter. This test for humans was approved by Institutional Review Board at Ohyama Hospital (Nishiwaki, Japan) and informed consent was obtained from all the participants. The study was conducted in Ohyama Hospital in accordance with the Declaration of Helsinki.

Intra-peritoneal glucose tolerance test (IPGTT)

IPGTT was carried out in $\mathrm{db} / \mathrm{db}$ mice fasted for $12 \mathrm{~h}$. PEG or DOPE ( $1 \mathrm{mg} / \mathrm{kg}$ body weight $)$ was orally administered to mice $30 \mathrm{~min}$ prior to intraperitoneal injection of glucose $(2 \mathrm{~g} / \mathrm{kg}$ body weight). After collection of blood $(10 \mu \mathrm{L})$ from the tail vein, the serum glucose levels were measured.

Statistical analysis

Statistical analysis was carried out using unpaired $t$-test, Dunnett's test, analysis of variance (ANOVA) followed by a Bonferonni correction, and ANOVA followed by Fisher's protected least significant difference (PLSD) test.

\section{Results}

DOPE increases cell surface localization of GLUT4, regardless of Akt activation

Initially, the effect of PEs on cellular GLUT4 distribution was examined in differentiated 3T3-L1-GLUT4myc adipocytes. DOPE $(1 \mu \mathrm{M})$ significantly increased cell surface localization of GLUT4, but such effect was not obtained with the other PEs such as DAPE, DLPE, and DPPE (Fig. 2A). This indicates that DOPE-induced increase in the cell surface GLUT4 levels is not due to the non-specific action of PEs.

DOPE is hydrolyzed into OA and lysoPE by phospholipase $\mathrm{A}_{2}\left(\mathrm{PLA}_{2}\right)$. FFAs such as LA, LnA, OA, and SA had no effect on cellular GLUT4 distribution (Fig. 2B). This implies that the effect of DOPE obtained here is not attributed to the DOPE metabolite OA. 


\section{Cellular Physiology Cell Physiol Biochem 2018;46:1985-1998 \begin{tabular}{l|l} 
DOI: 10.1159/000489439 & O 2018 The Author(s). Published by S. Karger AG, Basel \\
www.karger.com/cpb
\end{tabular} \\ Nishizaki: Inhibition of PKC $\alpha$-Driven GLUT4 Internalization}

Fig. 2. DOPE increases cell surface localization of GLUT4 in an Akt-independent manner. Differentiated 3T3-L1-GLUT4myc adipocytes were untreated and treated with PEs $(1 \mu \mathrm{M})(\mathrm{A})$ or FFAs $(30 \mu \mathrm{M})(\mathrm{B})$ as indicated for $20 \mathrm{~min}$, followed by Western blotting using an anti-c-myc antibody in the cytosolic (C) and plasma membrane fractions (M). (D) Cells transfected with the NC siRNA (NC) or the Akt1/2 siRNA (Akt1/2 KD) were untreated and treated with DOPE $(1 \mu \mathrm{M})$ for 20 min, followed by Western blotting using an anti-cmyc antibody in the cytosolic (C) and plasma membrane fractions (M). In the graphs, each column represents the mean $( \pm$ SEM) signal intensity for GLUT4 on the plasma membrane relative to that for whole cells $(n=4$ independent experiments). P values, ANOVA followed by a Bonferonni correction. NS, not significant. (C) Cells were untreated and treated with PEs $(1 \mu \mathrm{M})$ as indicated for $10 \mathrm{~min}$, followed by Western blotting. In the graph, each column represents the mean $( \pm$ SEM) signal intensity for phosphorylation at Thr308/309

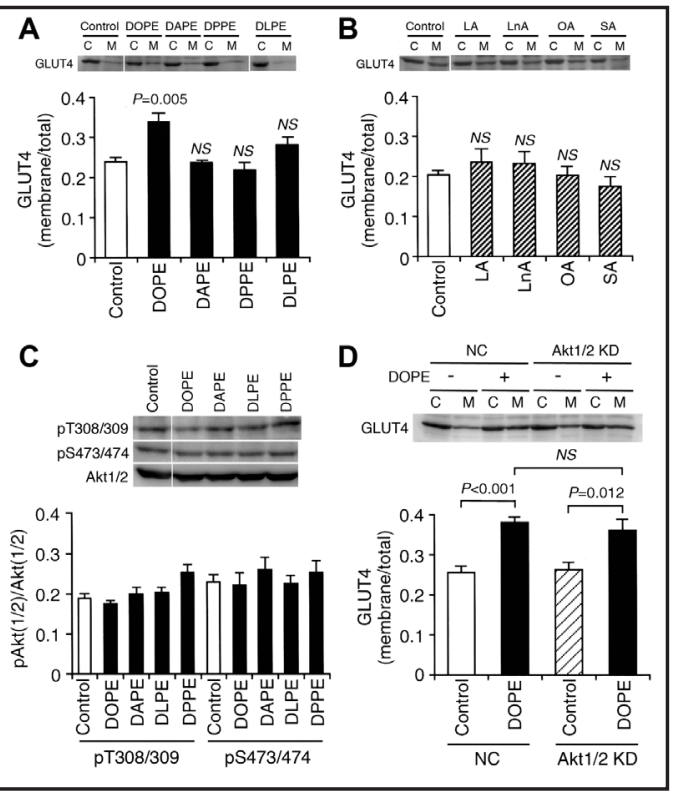
(pT308/309) or Ser473/474 (pS473/474) relative to that for Akt1/2 ( $\mathrm{n}=4$ independent experiments).

One could argue that an increase in the cell surface GLUT4 levels is due to stimulation of GLUT4 exocytosis or to inhibition of GLUT4 endocytosis. Akt is a key factor for GLUT4 exocytosis [1]. Akt1/2 is activated by being phosphorylated at Thr308/309 and Ser473/474. Of examined PEs DOPE did not affect Akt1/2 phosphorylation in differentiated 3T3-L1GLUT4myc adipocytes (Fig. 2C). This indicates that DOPE does not activate Akt.

DOPE-induced increase in the cell surface GLUT4 levels was not affected by knockingdown Akt1/2 (Fig. 2D), indicating no implication of Akt in the effect of DOPE. This suggests that DOPE increases cell surface localization of GLUT4 by inhibiting GLUT4 endocytosis rather than by stimulating GLUT4 exocytosis.

PKC $\alpha$ deficiency increases cell surface localization of GLUT4

PKC serves as transducers and modulators of insulin signaling [14], and $\mathrm{PKCl} / \zeta$ and - $\varepsilon$ participate in the regulation of GLUT4 translocation $[11,15]$. To see the direct effect of PKC on intracellular GLUT4 trafficking, the PKC isozymes were knocked-down. Notably, cell surface localization of GLUT4 was significantly increased only by knocking-down PKC $\alpha$ (Fig. 3A), while no effect was induced by knocking-down PKC $\gamma$ (Fig. 3B), PKC $\lambda /$ เ(Fig. 3C), PKC了 (Fig. 3D), or PKCE (Fig. 3E). This suggests that PKC $\alpha$ deficiency stimulates GLUT4 exocytosis or inhibits GLUT4 endocytosis; conversely, PKC $\alpha$ inhibits GLUT4 endocytosis or stimulates GLUT4 endocytosis.

PKC $\alpha$ knock-down increased cell surface localization of GLUT4 to an extent similar to that for DOPE, which occluded the effect of DOPE (Fig. 4). This raises the possibility that DOPE increases cell surface localization of GLUT4 by suppressing PKC $\alpha$ activation.

\section{DOPE suppresses PKC $\alpha$ activation}

To see the effect of DOPE on PKC, cell-free PKC assay was carried out. DOPE $(100 \mu \mathrm{M})$ had no inhibitory effect on basal activities of all the PKC isozymes examined here (Fig. 5A). The broad PKC activator phorbol 12-myristate 13-acetate (PMA) $(1 \mu \mathrm{M})$ activated PKC $\alpha$, and DOPE $(100 \mu \mathrm{M})$ obviously inhibited PMA-induced PKC $\alpha$ activation (Fig. 5B). In contrast, DOPE had no effect on PMA-induced activation of other PKC isozymes (data not shown).

To obtain further evidence for DOPE-induced suppression of PKC $\alpha$ activation, in situ PKC $\alpha$ assay using a FRET probe was performed in differentiated 3T3-L1-GLUT4myc adipocytes. As previously shown with $\mathrm{PKC} \varepsilon$ [13], a conformational change of PKC $\alpha$ from the inactive form to 


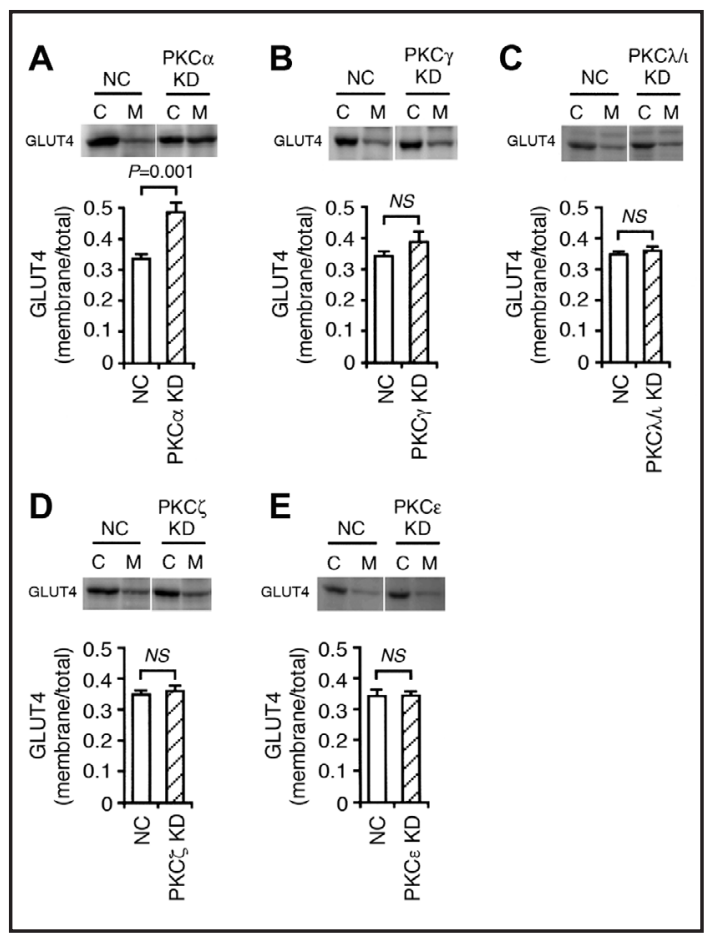

Fig. 3. PKC $\alpha$ deficiency increases cell surface localization of GLUT4. Differentiated 3T3-L1-GLUT4 myc adipocytes were transfected with the NC siRNA (NC) or the siRNAs for PKC $\alpha$ (PKC $\alpha$ KD) (A), $-\gamma(\mathrm{PKC} \gamma \mathrm{KD})(\mathrm{B}),-\lambda / \mathrm{\iota}(\mathrm{PKC} \lambda / \mathrm{\iota} \mathrm{KD})(\mathrm{C}),-\zeta(\mathrm{PKC} \zeta \mathrm{KD})$ (D), and $-\varepsilon$ (PKC $\varepsilon$ KD) (E), and $48 \mathrm{~h}$ after transfection Western blotting using an anti-c-myc antibody was performed in the cytosolic (C) and plasma membrane fractions (M). In the graphs, each column represents the mean $( \pm$ SEM) signal intensity for GLUT4 on the plasma membrane relative to that for whole cells ( $\mathrm{n}=4$ independent experiments). $\mathrm{P}$ values, unpaired t-test.

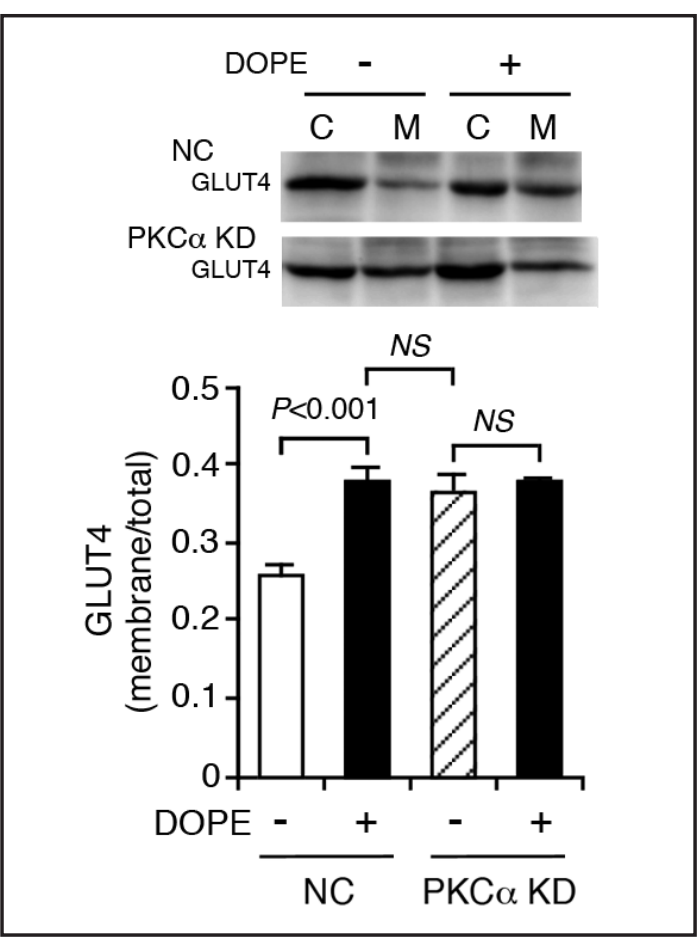

Fig. 4. PKC $\alpha \mu \mathrm{M}$ occludes DOPE-induced increase in the cell surface GLUT4 levels. Differentiated 3T3-L1GLUT4myc adipocytes were transfected with the NC siRNA (NC) or the PKC $\alpha$ siRNA (PKC $\alpha$ KD) were untreated and treated with DOPE $(1 \mu \mathrm{M})$ for $20 \mathrm{~min}$, followed by Western blotting using an anti-c-myc antibody in the cytosolic (C) and plasma membrane fractions (M). In the graph, each column represents the mean $( \pm$ SEM) signal intensity for GLUT4 on the plasma membrane relative to that for whole cells ( $n=4$ independent experiments). $\mathrm{P}$ value, ANOVA followed by a Bonferonni correction. NS, not significant.

the active form enhances the CFP signal intensity. Accordingly, a decrease and an increase in the FRET ratio (YFP signal intensity/CFP signal intensity) correspond to activation and inactivation of $\mathrm{PKC} \alpha$, respectively. PMA $(1 \mu \mathrm{M})$ drastically decreased the FRET ratio, and DOPE $(1 \mu \mathrm{M})$ abolished the effect of PMA (Fig. 6). Collectively, these results indicate that DOPE has the potential to suppress PKC $\alpha$ activation.

\section{DOPE restrains GLUT4 endocytic internalization by suppressing PKC $\alpha$ activation}

To confirm whether DOPE stimulates GLUT4 exocytosis or inhibits GLUT4 endocytosis, GLUT4 internalization assay was carried out. Insulin $(100 \mathrm{nM})$ increased cell surface localization of GLUT4 in differentiated 3T3-L1-GLUT4myc adipocytes (Fig. 7A). The effect of insulin was neutralized by 120 -min washing-out of insulin, but such neutralization was not found in the presence of DOPE $(1 \mu \mathrm{M})$ (Fig. 7A). Moreover, DOPE had no additive effect on insulin-induced increase in the cell surface GLUT4 levels (data not shown).

Insulin-induced increase in the cell surface GLUT4 levels was masked in PKC $\alpha$ deficient cells, and GLUT4 internalization was not found still after 120-min washing-out of insulin (Fig. 7B). Taken together, these results indicate that DOPE restrains GLUT4 endocytic internalization by suppressing PKC $\alpha$ activation, to retain cell surface GLUT4. 
Fig. 5. DOPE suppresses PMAinduced $\mathrm{PKC} \alpha$ activation in the cell-free PKC assay. (A) Activities of PKC isozymes as indicated were assayed in the absence (open column) and presence (closed column) of DOPE $(100 \mu \mathrm{M})$ under the cell-free conditions. In the graph, each value represents the mean $( \pm$ SEM) PKC activity (pmol/min)
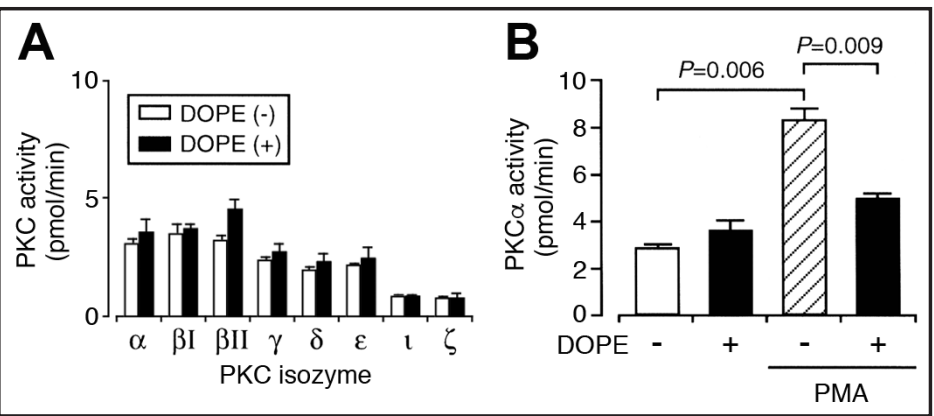
( $\mathrm{n}=4$ independent experiments).

(B) PKC $\alpha$ activity was assayed in the absence and presence of DOPE $(100 \mu \mathrm{M})$ together without and with PMA $(1 \mu \mathrm{M})$. In the graph, each value represents the mean $( \pm$ SEM) PKC $\alpha$ activity $(\mathrm{pmol} / \mathrm{min})(\mathrm{n}=4)$. P values, ANOVA followed by a Bonferonni correction.

DOPE facilitates glucose uptake into cells by targeting $P K C \alpha$

If DOPE increases cell surface GLUT4 levels, then itshould facilitate glucose uptake into cells. To address this point, glucose assay was performed using differentiated 3T3-L1-GLUT4myc adipocytes. Expectedly, DOPE enhanced glucose uptake into cells in a concentration (0.01-10 $\mu \mathrm{M})$-dependent manner, while such effect was not found with DAPE, DPPE, or DLPE (Fig. 8A). Glucose uptake was also enhanced by knockingdown $\mathrm{PKC} \alpha$, and no further enhancement in the glucose uptake was obtained by adding DOPE (Fig. 8B). These results indicate that DOPE enhances glucose uptake into adipocytes by inhibiting PKC $\alpha$.

DOPE efficiently lowers the blood glucose levels in type $2 \mathrm{DM}$

To finally see the effect of DOPE on whole body glucose homeostasis, OGTT was carried out in $\mathrm{db} / \mathrm{db}$ mice, an animal model of type $2 \mathrm{DM}$. The serum glucose levels elevated to approximately $600 \mathrm{mg} /$ $\mathrm{dL} 30 \mathrm{~min}$ after glucose loading, being still high (over $500 \mathrm{mg} / \mathrm{dL}$ ) $90 \mathrm{~min}$ after glucose loading (Fig. 9A). Oral administration with DOPE at doses ranging from 0.1 to 10 $\mathrm{mg} / \mathrm{kg}$ body weight significantly restricted an increase in the serum glucose levels after glucose loading as compared with that without DOPE administration (Fig. 9A). In contrast, no significant effect was obtained with DPPE (1mg/kg body weight, per os) (Fig. 9B).

A similar effect of DOPE was also obtained with the intra-peritoneal glucose tolerance test (IPGTT) (Fig. 10). This indicates that pre-administration of DOPE had no effect on glucose absorption in the digestive tract.

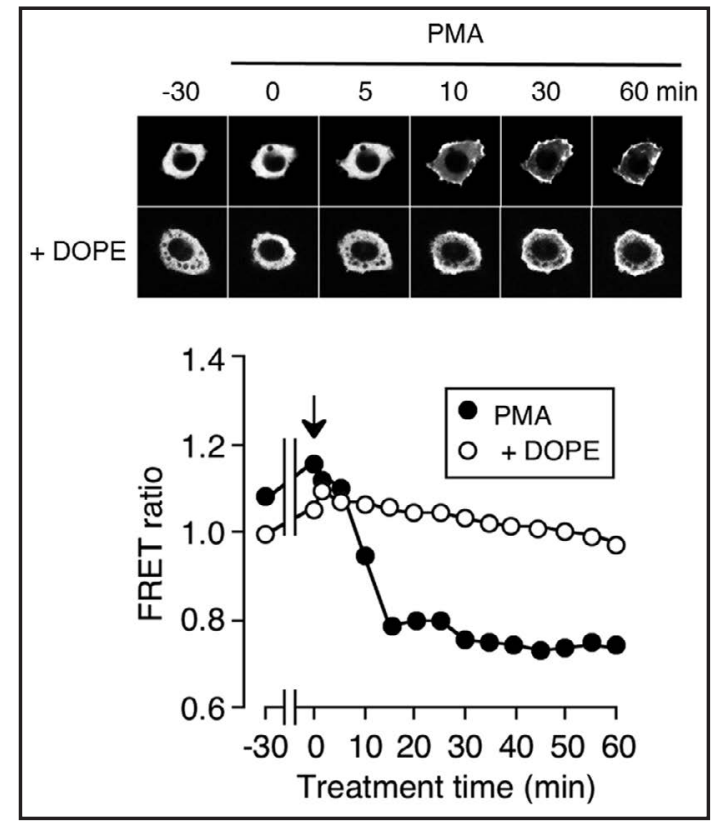

Fig. 6. DOPE suppresses PMA-induced PKC $\alpha$ activation in in situ PKC assay. The YFP and CFP signals were monitored in differentiated 3T3-L1-GLUT4myc adipocytes expressing the FRET probe at periods of time as indicated in the presence of PMA $(1 \mu \mathrm{M})$ together without and with DOPE $(1 \mu \mathrm{M})$. FRET images in cells are shown in the upper column. In the graph, each point represents the FRET ratio (YFP signal results were obtained with 4 independent experiments. intensity/CFP signal intensity). Note that similar

\section{KARGER}


Fig. 7. DOPE and PKC $\alpha$ deficiency restrain GLUT4 endocytic internalization. (A) Differentiated 3T3-L1GLUT4myc adipocytes were treated with insulin (Ins) (100 nM) for $30 \mathrm{~min}$. Then, insulin was washed out in the absence and presence of DOPE $(1 \mu \mathrm{M})$ for $120 \mathrm{~min}$, followed by Western blotting using an antic-myc antibody in the cytosolic (C) and plasma membrane fractions (M). -30, 0, and $120 \mathrm{~min}$ indicate before treatment with insulin, after 30-min treatment with insulin, and after 120-min washing-out of insulin in the absence and presence of DOPE, respectively. (B) Cells transfected with the NC siRNA (NC) or the PKC $\alpha$ siRNA (PKC $\alpha$ KD) were treated with insulin (Ins) (100 nM)

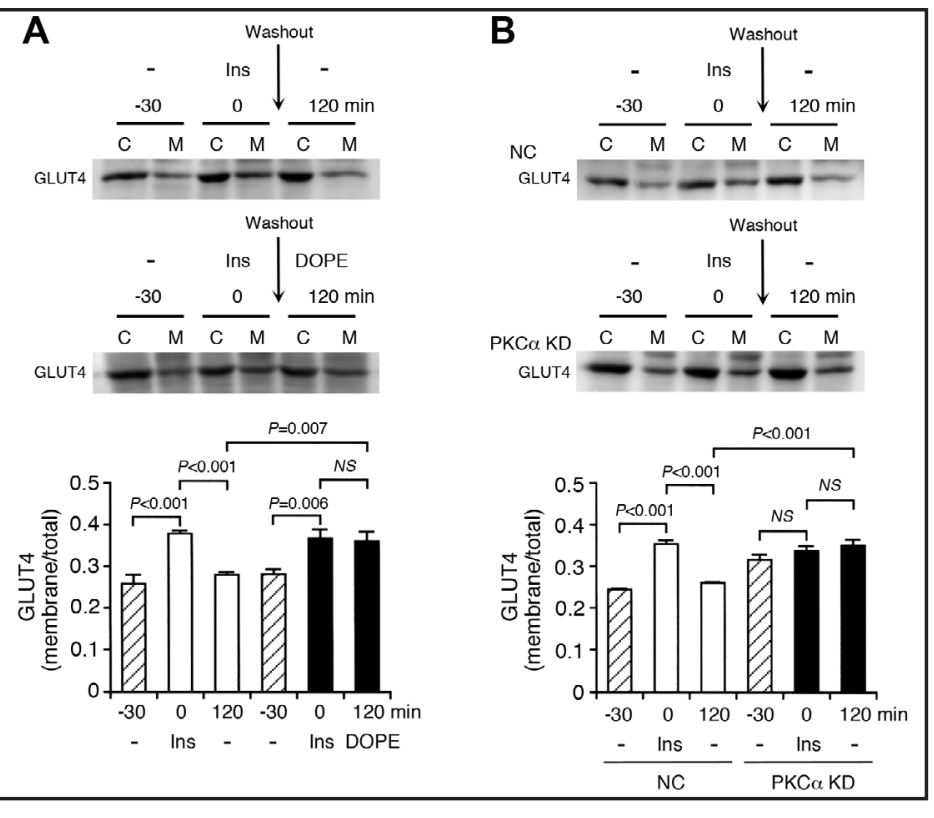
for $30 \mathrm{~min}$. Then, insulin was washed out for $120 \mathrm{~min}$, followed by Western blotting using an anti-c-myc antibody in the cytosolic (C) and plasma membrane fractions (M). -30, 0, and 120 min indicate before treatment with insulin, after 30-min treatment with insulin, and after 120-min washing-out of insulin, respectively. In the graphs, each column represents the mean ( \pm SEM) signal intensity for GLUT4 on the plasma membrane relative to that for whole cells $(n=4$ independent experiments). $P$ values, ANOVA followed by a Bonferonni correction. NS, not significant.

Fig. 8. DOPE and PKC $\alpha$ deficiency enhance glucose uptake into cells. (A) Differentiated 3T3-L1-GLUT4 myc adipocytes were untreated and treated with DOPE at concentrations as indicated, DAPE $(1 \mu \mathrm{M})$, DPPE $(1 \mu \mathrm{M})$, or DLPE $(1 \mu \mathrm{M})$ for 2 $\mathrm{h}$ at $37^{\circ} \mathrm{C}$, followed by glucose assay. (B) Cells transfected with the NC siRNA (NC) or the PKC $\alpha$ siRNA

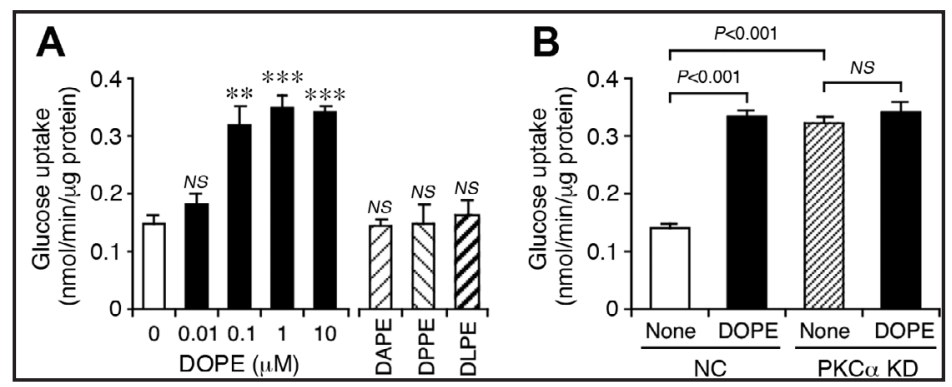

(PKC KD) were untreated and treated with DOPE $(1 \mu \mathrm{M})$ for $2 \mathrm{~h}$ at $37^{\circ} \mathrm{C}$, followed by glucose assay. In the graphs, each column represents the mean $( \pm$ SEM) glucose uptake $(\mathrm{nmol} / \mathrm{min} / \mu \mathrm{g}$ protein)( $\mathrm{n}=6$ independent experiments). ${ }^{* *} \mathrm{P}<0.01,{ }^{* * *} \mathrm{P}<0.001$, $\mathrm{P}$ values; ANOVA followed by a Bonferroni correction. NS, not significant.

To further examine the effect of DOPE on whole body glucose homeostasis, OGTT was performed in seven type 2 DM patients at ages ranging from 54 to 69 years old ( 5 males and 2 females) with the HbA1c value (NGSP) over 5.8\%, who take a variety of anti-DM drugs (Table 1). Oral intake with DOPE (approximately $6 \mathrm{mg}$ ) beneficially restricted an increase in the blood glucose levels after glucose loading in five of 7 subjects (Fig. 11A-G). Moreover, OGTT was performed in 7 healthy human subjects at ages ranging from 37 to 70 years old (4 males and 3 females), and a restriction of increase in the blood glucose levels after glucose loading, especially $60 \mathrm{~min}$ after glucose loading, was found in six of 7 subjects by taking DOPE (approximately $6 \mathrm{mg}$ ), without hypoglycemic attack (Fig. 12A-G). 
Fig. 9. OGTT using type $2 \mathrm{DM}$ model mice. After a 12-h fast, DOPE at doses as indicated (A) or DPPE $(1 \mathrm{mg} / \mathrm{kg}$ body weight) (B) was orally administered to $\mathrm{db} / \mathrm{db}$ mice $30 \mathrm{~min}$ prior to loading glucose ( $2 \mathrm{~g} / \mathrm{kg}$ body weight). The blood was collected at periods of time as indicated, and the serum glucose concentration was calculated. In the graphs, each point represents the mean $( \pm \mathrm{SEM})$ serum glucose concentration $(\mathrm{mg} / \mathrm{mL})(\mathrm{n}=8$ independent
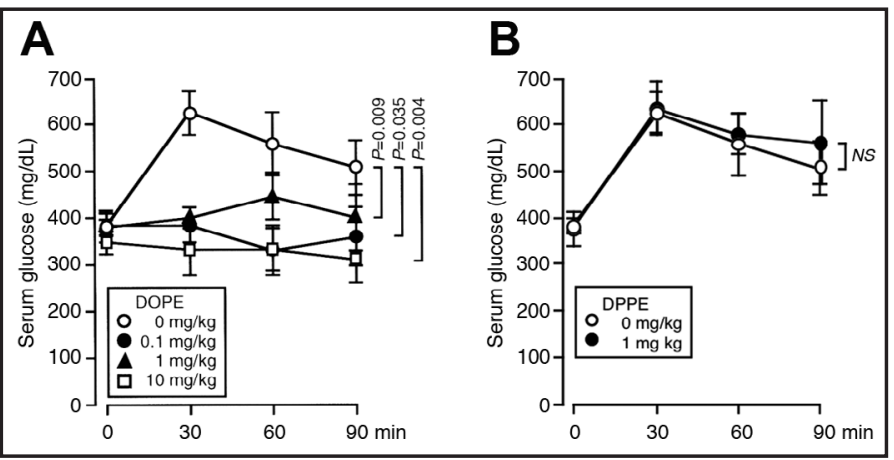
mice). P values, ANOVA followed by Fisher's PLSD test. NS, not significant.

Fig. 10. IPGTT using type 2 DM model mice. After a 12-h fast, PEG or DOPE (1 mg/kg body weight) was orally administered to $\mathrm{db} / \mathrm{db}$ mice $30 \mathrm{~min}$ prior to intraperitoneal injection of glucose ( $2 \mathrm{~g} / \mathrm{kg}$ body weight). The blood was collected at periods of time as indicated, and the serum glucose concentration was calculated. In the graphs, each point represents the mean $( \pm$ SEM) serum glucose concentration $(\mathrm{mg} / \mathrm{mL})(\mathrm{n}=4$ independent mice). $\mathrm{P}$ value, ANOVA followed by Fisher's PLSD test.

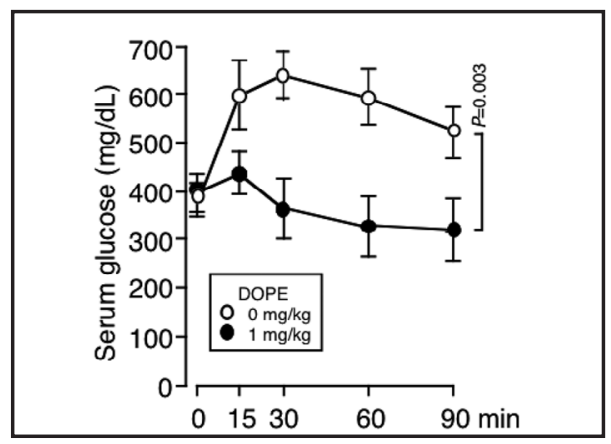

Fig. 11. OGTT using type 2 DM human subjects. After a 12-h fast, glucose (75 mg) and lecithin containing DOPE (approximately $6 \mathrm{mg}$ ) were simultaneously taken, and the blood glucose levels at periods of time as indicated were measured using a blood glucose meter.

\section{Discussion}

In the present study, DOPE increased cell surface localization of GLUT4 in differentiated 3T3-L1-GLUT4 myc adipocytes, although such effect
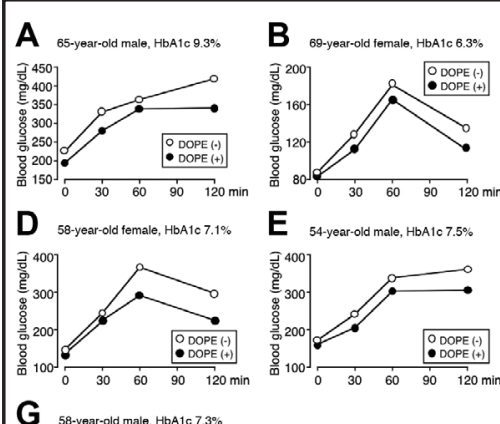

E 54 -rear-ald
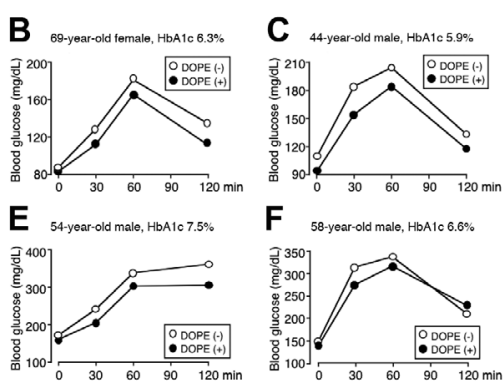

F 56 -year-old male, HbA10 $6.6 \%$

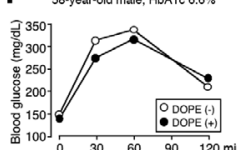

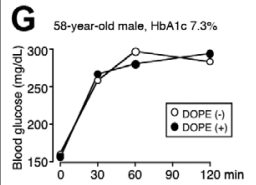
was not obtained with any other PEs examined here. This implies that the effect of DOPE is not due to the non-specific action of PEs.

One could argue that DOPE-induced increase in the cell surface GLUT4 levels is ascribed to stimulation of GLUT4 exocytosis or to inhibition of GLUT4 endocytosis. In response to insulin, GLUT4 is translocated towards the cell surface and appears on the plasma membrane, to transport extracellular glucose into cells. Thereafter, GLUT4 is internalized into cells. Akt, which is activated by being phosphorylated at the threonine and serine residues, plays a central role in insulin-induced GLUT4 translocation and exocytosis [1]. DOPE had no effect on phosphorylation of Akt1/2 at Thr308/309 and Ser473/474 in 3T3-L1-GLUT4myc adipocytes, indicating that DOPE does not activate Akt. Moreover, DOPE-induced increase in the cell surface GLUT4 levels was not affected by knocking-down Akt1/2, which excludes the contribution of Akt-regulated GLUT4 exocytosis to the effect of DOPE.

In the present study, insulin $(100 \mathrm{nM})$ induced approximately 1.4-fold increase in the cell surface localization of GLUT4. One might claim that the effect seems to be weaker as compared 
Table 1. Prescription drugs for treatment of DM

\begin{tabular}{|c|c|c|c|}
\hline & Age/Gender & HbA1c (NGSP) & Drugs for a day \\
\hline Case A & 65/Male & $9.3 \%$ & $\begin{array}{l}\text { Pioglitazone hydrochloride }(15 \mathrm{mg}) / \text { Glimepiride }(1 \mathrm{mg}) 1 \text { tablet after breakfast } \\
\text { Metformin hydrochloride }(250 \mathrm{mg}) 1 \text { tablet after each breakfast and supper } \\
\text { Voglibose }(0.3 \mathrm{mg}) 1 \text { tablet before supper }\end{array}$ \\
\hline Case B & 69/Female & $6.3 \%$ & Glimepiride $(1 \mathrm{mg}) 1$ tablet after breakfast \\
\hline Case C & 44/Male & $5.9 \%$ & $\begin{array}{l}\text { Vildagliptin }(50 \mathrm{mg}) / \text { Metformin hydrochloride }(250 \mathrm{mg}) 1 \text { tablet after each breakfast and supper } \\
\text { Empagliflozin }(10 \mathrm{mg}) 1 \text { tablet after breakfast }\end{array}$ \\
\hline Case D & 58/Female & $7.1 \%$ & $\begin{array}{l}\text { Glimepiride }(1 \mathrm{mg}) 1 \text { tablet after breakfast } \\
\text { Metformin hydrochloride }(250 \mathrm{mg}) 1 \text { tablet after each breakfast and supper }\end{array}$ \\
\hline Case E & 54/Male & $7.5 \%$ & $\begin{array}{l}\text { Pioglitazone hydrochloride }(15 \mathrm{mg}) / \text { Glimepiride }(1 \mathrm{mg}) 1 \text { tablet after breakfast } \\
\text { Voglibose }(0.3 \mathrm{mg}) 1 \text { tablet three times before meal }\end{array}$ \\
\hline Case F & 58/Male & $6.6 \%$ & $\begin{array}{l}\text { Pioglitazone hydrochloride }(15 \mathrm{mg}) / \text { Glimepiride }(1 \mathrm{mg}) 1 \text { tablet after breakfast } \\
\text { Vildagliptin }(50 \mathrm{mg}) / \text { Metformin hydrochloride }(500 \mathrm{mg}) 1 \text { tablet after each breakfast and supper } \\
\text { Miglitol }(50 \mathrm{mg}) 1 \text { tablet three times before meal }\end{array}$ \\
\hline Case G & 58/Male & $7.3 \%$ & $\begin{array}{l}\text { Saxagliptin hydrate }(5 \mathrm{mg}) 1 \text { tablet before breakfast } \\
\text { Dapagliflozin propylene glycolate hydrate }(5 \mathrm{mg}) 1 \text { tablet after breakfast } \\
\text { Metformin hydrochloride }(500 \mathrm{mg}) 1 \text { tablet after each breakfast and supper }\end{array}$ \\
\hline
\end{tabular}

to the 2-3 fold increase as previously shown $[16,17]$. It has been confirmed in the Western blot analysis using antibodies against the cytosolic marker LDH and the plasma membrane marker cadherin that the cytosolic and plasma membrane components used here are successfully separated, and GLUT4 was quantified in the plasma membrane components. In addition, insulin stimulated GLUT4 translocation from the cytosol to the plasma membrane in 3T3-L1GLUT4myc adipocytes in a concentration (1 $\mathrm{nM}-1$ $\mu \mathrm{M})$-dependent manner, the extent reaching nearly
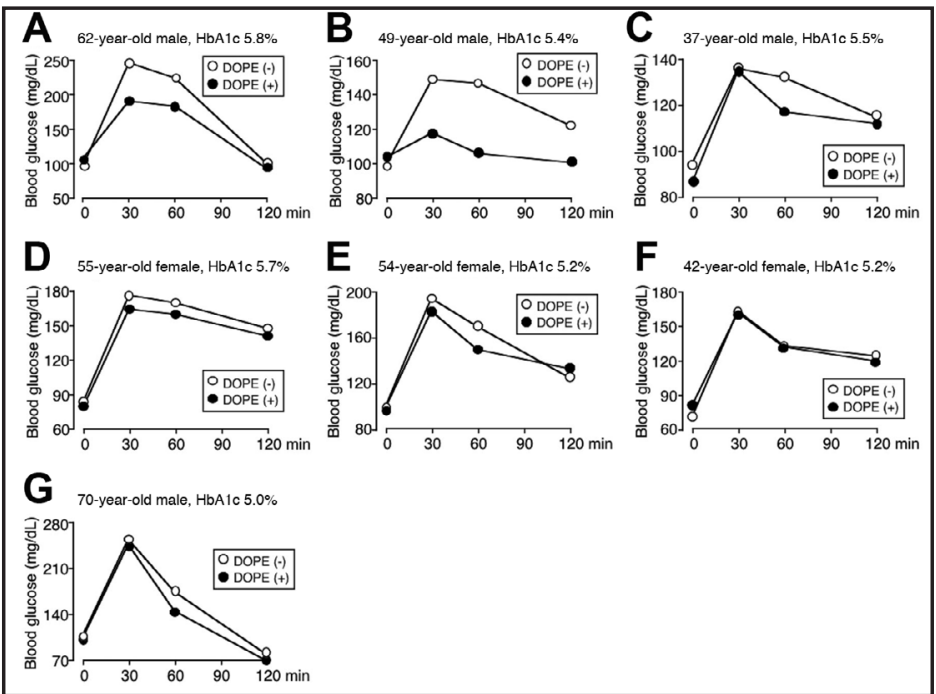

Fig. 12. OGTT using healthy human subjects. After a 12-h fast, glucose (75 mg) and lecithin containing DOPE (approximately $6 \mathrm{mg}$ ) were simultaneously taken, and the blood glucose levels at periods of time as indicated were measured using a blood glucose meter. 2 -fold of the basal levels at $1 \mu \mathrm{M}$ [12]. These results explain that the present GLUT4 translocation assay accurately monitors insertion of GLUT4 into the plasma membrane. In the GLUT4 internalization assay, DOPE significantly prevented endocytic internalization of GLUT4 localized on the plasma membrane after insulin stimulation. This indicates that DOPE increases cell surface localization of GLUT4 due to inhibition of GLUT4 endocytosis rather than to stimulation of GLUT4 exocytosis.

$\operatorname{PKC} \lambda / \mathrm{l},-\zeta$, and $-\varepsilon$ are recognized to stimulate GLUT4 translocation and exocytosis $[11,14$, 15], but little is known about the implication of PKC $\alpha$ in the regulation of GLUT4 trafficking. One of the major findings in the present study is that cell surface localization of GLUT4 is increased by knocking-down PKC $\alpha$, but not other PKC isozymes, that occludes the effect of DOPE. This suggests that DOPE increases cell surface localization of GLUT4 in a fashion that mimics the effect of PKC $\alpha$ deficiency. As is the case with DOPE, PKC $\alpha$ deficiency increased 
cell surface localization of GLUT4 and cancelled GLUT4 endocytic internalization after insulin stimulation. This raises the possibility that DOPE inhibits GLUT4 endocytosis and persistently retains GLUT4 on the plasma membrane by targeting PKC $\alpha$. To obtain evidence for this, PKC assay was carried out. In the cell-free PKC assay, DOPE markedly suppressed PMA-induced PKC $\alpha$ activation, although basal PKC $\alpha$ activity was not affected. PKC contains the binding sites of a variety of lipids such as unsaturated free fatty acids, diacylglycerol, and phosphatidylserine [18]. DOPE, in the light of the fact, appears to inhibit the active form of $\mathrm{PKC} \alpha$ by direct interaction.

In the in situ PKC $\alpha$ assay, DOPE abolished PMA-induced PKC $\alpha$ activation in differentiated adipocytes, supporting the notion for DOPE-induced inhibition of activated PKC $\alpha$. Taken together, these results indicate that DOPE restrains endocytic internalization of GLUT4 and retains GLUT4 on the plasma membrane by suppressing PKC $\alpha$ activation, causing a relative increase in the cell surface GLUT4 levels. Notably, DOPE and PKC $\alpha$ deficiency increased cell surface localization of GLUT4 without insulin stimulation. This may imply that DOPE and PKC $\alpha$ deficiency inhibit GLUT4 endocytosis not only after insulin stimulation but under the process of spontaneous GLUT4 trafficking.

Accumulating evidence has pointed to the role of PKC $\alpha$ in the regulation of protein endocytosis. Nephrin forms a complex with protein interacting with c kinase-1 (PICK1) and PKC $\alpha$. When nephrin is phosphorylated at Thr1120 and Thr1125 by PKC $\alpha, \beta$-arrestin is recruited to the complex, which triggers nephrin endocytosis $[19,20]$. PKC $\alpha$ and G-protein-coupled receptor kinase (GRK) promote $\beta$-arrestin-dependent clathrin coating and endocytosis of glucagon receptor [21]. PKC $\alpha$, that is translocated to the plasma membrane by interacting with PICK1, phosphorylates the $\alpha$-amino-3-hydroxy-5-methyl-4isoxazolepropionic acid (AMPA) receptor subunit GluR2 at Ser880, and then, phosphorylated GluR2 is internalized together with PICK1 [22]. PKC $\alpha$, in the light of these facts, may promote GLUT4 endocytosis. To obtain evidence for this notion, further experiments need to be carried out.

DOPE enhanced glucose uptake into cells in a concentration (0.01-10 $\mu \mathrm{M})$-dependent manner, although DAPE, DPPE, and DLPE had no effect. PKC $\alpha$ deficiency also enhanced glucose uptake to an extent similar to that for DOPE, and no further enhancement in the glucose uptake was obtained by adding DOPE. Overall, it is concluded that DOPE retains cell surface GLUT4 by suppressing PKC $\alpha$-driven endocytic internalization of GLUT4, to enhance glucose uptake into adipocytes.

The question to be addressed is how extracellularly applied DOPE is rapidly transported to the inner leaflet or the cytosol across the plasma membrane. The mechanism for lipid transport across the lipid bilayer is not fully understood. DOPE might enter cells by free diffusion. Free diffusion, however, would be inefficient for rapid transport. Another possibility is that DOPE might be transported by flip-flop movement of phospholipids in the lipid bilayer. Spontaneous flip-flop motion is restricted and very rare as compared with spontaneous lateral motion, although ceramide is shown to induce flip-flop motion of other lipids [23]. In contrast, membrane protein transporter-mediated flip-flop movement allows rapid diffusion of lipids across the plasma membrane [24-26]. Emerging evidence has pointed to ATP-binding cassette $(\mathrm{ABC})$ transporters as a membrane protein transporter for lipids, that mediate the bidirectional transfer of lipids inside and outside cells. Indeed, ABC transporter A1 (ABCA1) mediates the transfer of cellular phospholipid and free cholesterol [27]. The present in situ PKC $\alpha$ assay clearly demonstrates that extracellularly applied DOPE inhibited activated PKC $\alpha$ in cells. This confirms that DOPE enters cells and functions in cells. Exogenous DOPE, thus, appears to be transported inside cells by an $\mathrm{ABC}$ transporter-like transporter.

DOPE contains OA at the $\alpha$ and $\beta$ position, which is hydrolyzed into OA and lysoPE by $\mathrm{PLA}_{2}$. One would wonder whether the effects of DOPE on GLUT4 trafficking and glucose uptake are due to its metabolites OA and lysoPE. OA, however, had no effect on cellular GLUT4 distribution, which rules out the implication of OA in the effects of DOPE. As discussed above, the primary site of actions of DOPE is PKC $\alpha$. In the cell-free PKC assay without phospholipase

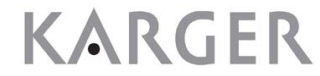


$\mathrm{A}_{2}$, DOPE suppressed PMA-induced PKC $\alpha$ activation. This accounts for the action of DOPE itself, but not its metabolites OA and lysoPE, on PKC $\alpha$ activity. Consequently, the effects of DOPE on GLUT4 trafficking and glucose uptake would not be attributed to the action of the DOPE metabolites, even though the possibility for participation of lysoPE is not completely excluded.

In the OGTT using type 2 DM model mice, oral administration with DOPE $0.1-10 \mathrm{mg} /$ kg body weight) effectively restricted an increase in the serum glucose levels after glucose loading, while such effect was not obtained with DPPE $(1 \mathrm{mg} / \mathrm{kg}$, per os). This implies that DOPE lowers blood glucose by the specific action distinct from other PEs. Then, the question raised is how orally administered DOPE is delivered to fat cells in the adipose tissues to lower blood glucose within $60 \mathrm{~min}$. In the digestive tract, triacylglycerol (TAG) is hydrolyzed by the enzyme pancreatic lipase, to release FFAs and monoglycerides. FFAs and monoglycerides associate with bile salts and phospholipids are dissolved by forming micelles and enter the enterocytes by diffusion, followed by re-synthesis of TAG in the endoplasmic reticulum. Synthesized TAG and fat-soluble substances are packed into the lipoproteins chylomicrons. Chylomicrons are released by exocytosis at the basolateral surface of the enterocytes, enter the lacteals and lymphatic capillaries, and then flow into the circulation via lymphatic vessels. Chylomicrons deliver absorbed TAG to the whole body's cells, and FFAs and monoglycerides released by lipoprotein lipase-catalyzed hydrolysis of chylomicrons diffuse into cells. Likewise, orally administered DOPE would be absorbed into the enterocytes by forming micelles and delivered to the adipose tissue, then entering fat cells, where DOPE functions to lower blood glucose. It would be possible that these processes are accomplished within $60 \mathrm{~min}$, as found in the present study. In further support of this possibility, diDCP-LA-PE also lowered the serum glucose levels from $60 \mathrm{~min}$ after oral administration in the OGTT using $\mathrm{db} / \mathrm{db}$ mice [11]. It remains an open question whether DOPE, that is delivered to the liver via the portal vein or the pancreas as well, exhibits an effect on glucose homeostasis.

In the OGTT using type 2 DM patients, a beneficial restriction of increase in the blood glucose levels after glucose loading was obtained with DOPE $(\sim 6 \mathrm{mg})$ in five of 7 subjects. Surprisingly, the HbA1c value in Case A, who took a sulfonylurea, a thiazolidine derivative, a biguanide, and an $\alpha$-glucosidase inhibitor (Table 1 ), dropped from 9.3 to $8.4 \%$ by additionally taking DOPE $(\sim 1.2 \mathrm{mg})$ after every meal for two months. This indicates that DOPE may be effective in the glycemic control of type 2 DM. Oral intake with DOPE ( $6 \mathrm{mg})$ also restricted an increase in the blood glucose levels $60 \mathrm{~min}$ after glucose loading in six of 7 healthy human subjects, but none of them had hypoglycemic attack. Taken together, these results indicate that DOPE has the potential to restrict an increase in the blood glucose levels after meal for both healthy and type 2 DM patients. GLUT4 is preferentially expressed in skeletal muscle cells as well as adipocytes. Skeletal muscle cells are the major site of glucose disposal in mammals. It is unknown whether DOPE enhances glucose uptake into skeletal muscle cells

Fig. 13. A hypothetic diagram underlying DOPE-induced inhibition of PKC $\alpha$-driven GLUT4 endocytic internalization. Insulin activates Akt through a pathway along an insulin receptor/IRS-1/PI3K/PDK1/ Akt axis (1)). In response to Akt, the vesicles containing GLUT4 are translocated towards the cell surface (2), to increase presence of GLUT4 on the plasma membrane bearing glucose uptake into cells.

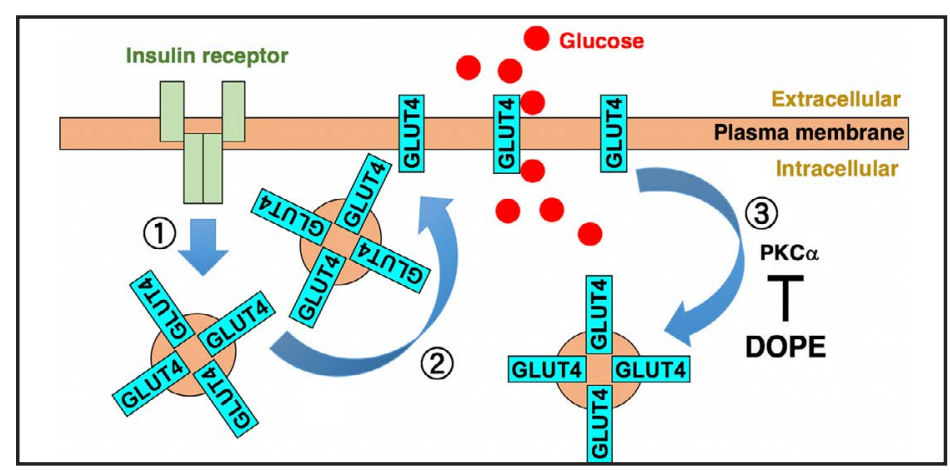
Thereafter, GLUT4 on the plasma membrane is internalized under the regulation of PKC $\alpha$ (3). DOPE suppresses PKC $\alpha$ activation, resulting in the inhibition of GLUT4 endocytic internalization and the persistent retention of GLUT4 on the plasma membrane. 
by the mechanism same as adipocytes. The OGTT results, however, strongly suggest that DOPE acts on skeletal muscle cells too.

\section{Conclusion}

In summary, the results of the present study show that DOPE restrains GLUT4 endocytic internalization by suppressing PKC $\alpha$ activation, to retain and relatively increase cell surface GLUT4, thereby enhancing glucose uptake into cells (Fig. 13) and that the action of DOPE restricts an increase in the blood glucose levels after glucose loading for type 2 DM model mice and human patients as well as healthy persons. The mechanism for DOPE-induced reduction of the blood glucose levels is different from that of any DM drug currently used. DOPE, accordingly, could be developed as a novel and promising drug for type 2 DM therapy.

\section{Abbreviations}

DOPE (1, 2-Dioleoyl-sn-glycero-3-phosphoethanolamine); DAPE (1, 2-Diarachidonoylsn-glycero-3-phosphoethanolamine); DLPE (1, 2-Dilinoleoyl-sn-glycero-3-phosphoethanolamine); DPPE (1, 2-Dipalmitoleoyl-sn-glycero-3-phosphoethanolamine); PE (Phosphatidylethanolamine); OA (Oleic acid); LA (Linoleic acid); LnA (Linolenic acid); SA (Stearic acid); FFAs (Free fatty acids); diDCP-LA-PE (1, 2-O-bis-[8-\{2-(2-Pentyl-cyclopropylmethyl)cyclopropyl\}-octanoyl]-sn-glycero-3-phosphatidylethanolamine); PEG (Polyethylene glycol)); LDH (Lactate dehydrogenase); BSA (Bovine serum albumin); FRET (Föerster resonance energy transfer); OGTT (Oral glucose tolerance test); IPGTT (Intra-peritoneal glucose tolerance test); DM (Diabetes mellitus); PMA (Phorbol 12-myristate 13-acetate); RTK (Receptor tyrosine kinase); IRS-1 (Insulin receptor substrate 1); PI3K (Phosphatidylinositol 3 kinase); $\mathrm{PI}\left(3\right.$ (4,5) $\mathrm{P}_{3}$ Phosphatidylinositol 3, 4,5-triphosphate); PI(4 (5) $\mathrm{P}_{2}$ Phosphatidylinositol 4, 5-biphosphate); PDK1 (3-Phosphoinositide-dependent protein kinase 1); Arf (ADP-ribosylation factor); HPLC (High performance liquid chromatography); siRNA (Small interfering RNA); $\mathrm{db} / \mathrm{db}\left(B K S . C g-+L e p^{\mathrm{db}} /+L e b^{\mathrm{db}} / \mathrm{Jcl}\right.$ ); ANOVA (Analysis of variance); PLSD (Protected least significant difference); PLA 2 (Phospholipase $\mathrm{A}_{2}$ ); IPGTT (Intra-peritoneal glucose tolerance test); PICK1 (Protein interacting with c kinase-1); GRK (G-protein-coupled receptor kinase); AMPA ( $\alpha$-Amino-3-hydroxy-5-methyl-4-isoxazolepropionic acid); ABC (ATP-binding cassette); ABCA1 (ABC transporter A1); TAG (Triacylglycerol).

\section{Acknowledgements}

I thank Prof. A. Gotoh (Hyogo College of Medicine, Nishinomiya, Japan) for discussion and Dr. T. Ohyama (Ohyama Hospital, Nishiwaki, Japan) for assistance of human OGTT. I have no sponsorship or funding arrangements relating to my research and I have no competing financial interests.

\section{References}

1 Leto D, Saltiel AR: Regulation of glucose transport by insulin: traffic control of GLUT4. Nat Rev Mol Cell Biol 2012;13:383-396.

2 Song G, Ouyang G, Bao S: The activation of Akt/PKB signaling pathway and cell survival. J Cell Mol Med 2005;9:59-71.

-3 Yang J, Cron P, Thompson V, Good VM, Hess D, Hemmings BA, Barford D: Molecular mechanism for the regulation of protein kinase B/Akt by hydrophobic motif phosphorylation. Mol Cell 2001;9:1227-1240. 


\section{Cellular Physiology Cell Physiol Biochem 2018;46:1985-1998 \begin{tabular}{l|l} 
DOI: 10.1159/000489439 & and Biochemistry \\
Published online:TMay 02, 2018 & $\begin{array}{l}\text { O 2018 The Author(s). Published by S. Karger AG, Basel } \\
\text { www.karger.com/cpb }\end{array}$
\end{tabular}}

Nishizaki: Inhibition of PKC $\alpha$-Driven GLUT4 Internalization

4 Shin HW, Nakayama K: Guanine nucleotide-exchange factors for arf GTPases: their diverse functions in membrane traffic. J Biochem 2004;136:761-767.

5 Deeba F, Tahseen HN, Sharad KS, Ahmad N, Akhtar S, Saleemuddin M, Mohammad O: Phospholipid diversity: Correlation with membrane-membrane fusion events. Biochim Biophys Acta 2005;1669:170181.

6 Emoto K, Kobayashi T, Yamaji A, Aizawa H, Yahara I, Inoue K, Umeda M: Redistribution of phosphatidylethanolamine at the cleavage furrow of dividing cells during cytokinesis. Proc Natl Acad Sci USA 1996;93:12867-12872.

-7 Emoto K, Toyama-Sorimachi N, Karasuyama H, Inoue K, Umeda M: Exposure of phosphatidylethanolamine on the surface of apoptotic cells. Exp Cell Res 1997;232:430-434.

-8 Ichimura Y, Kirisako T, Takao T, Satomi Y, Shimonishi Y, Ishihara N, Mizushima N, Tanida I, Kominami E, Ohsumi M, Noda T, Ohsumi Y: A ubiquitin-like system mediates protein lipidation. Nature 2000;408:488492.

9 Yaguchi T, Nagata T, Nishizaki, T: 1, 2-Dilinoleoyl-sn-glycero-3- phosphoethanolamine ameliorates agerelated spatial memory deterioration by preventing neuronal cell death. Behav Brain Funct 2010;6:52.

10 Tuschiya A, Kanno T, Nishizaki T: Dipalmitoleoylphosphoethanolamine as a PP2A enhancer obstructs insulin signaling by promoting Ser/Thr dephosphorylation of Akt. Cell Physiol Biochem 2014;34:617-627.

11 Nishizaki T, Gotoh A, Shimizu T, Tanaka A: The phosphatidylethanolamine derivative diDCP-LA-PE mimics intracellular insulin signaling. Sci Rep 2016;6: 27267.

12 Tsuchiya A, Kanno T, Nishizaki T: PI3 kinase directly phosphorylates Akt1/2 at Ser473/474 in the insulin signal transduction pathway. J Endocrinol 2013;220: 49-59.

13 Kanno T, Tsuchiya A, Shimizu T, Mabuchi M, Tanaka A, Nishizaki T: DCP-LA activates cytosolic PKC $\varepsilon$ by interacting with the phosphatidylserine binding/associating sites Arg50 and Ile89 in the C2-like domain. Cell Physiol Biochem 2015;37:193-200.

-14 Sampsona SR, Cooperb DR: Specific protein kinase C isoform as transducers and modulators of insulin signaling. Mol Genet Metab 2006;89:32-47.

15 Tsuchiya A, Kanno T, Nishizaki T: Diacylglycerol promotes GLUT4 translocation to the cell surface in a

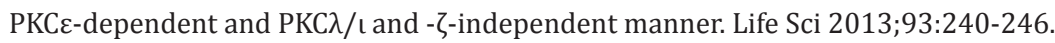

16 Wang L, Hayashi H, Ebina Y: Transient Effect of Platelet-derived Growth Factor on GLUT4 Translocation in 3T3-L1 Adipocytes. J Biol Chem 1999;274:19246-19253.

17 Emoto M, Klarlund JK, Waters SB, Hu V, Buxton JM, Chawla A, Czech MP: A role for phospholipase D in GLUT4 glucose transporter translocation. J Biol Chem 2000;275:7144-7151.

18 Steinberg SF: Structural basis of protein kinase C isoform function. Physiol Rev 2008;88:1341-1378.

-19 Quack I, Woznowski M, Potthoff SA, Palmer R, Königshausen E, Sivritas S, Schiffer M, Stegbauer J, Vonend O, Rump LC, Sellin L: PKC $\alpha$ mediates $\beta$-arrestin2-dependent nephrin endocytosis in hyperglycemia. J Biol Chem 2011;286:12959-12970.

20 Tossidou I, Teng B, Menne J, Shushakova N, Park JK, Becker JU, Modde F, Leitges M, Haller H, Schiffer M: Podocytic PKC-alpha is regulated in murine and human diabetes and mediates nephrin endocytosis. PLoS One 2010;5:e10185.

-21 Krilov L, Nguyen A, Miyazaki T, Unson CG, Williams R, Lee NH, Ceryak S, Bouscarel B: Dual mode of glucagon receptor internalization: role of PKC $\alpha$, GRKs and $\beta$-arrestins. Exp Cell Res 2011;317:2981-2994.

22 Bell JD, Park E, Ai J, Baker AJ: PICK1-mediated GluR2 endocytosis contributes to cellular injury after neuronal trauma. Cell Death Differ 2009;16:1665-1680.

-23 Contreras FX, Sánchez-Magraner L, Alonso A, Goñi FM: Transbilayer (flip-flop) lipid motion and lipid scrambling in membranes. FEBS Lett 2010;584:1779-1786.

24 Kamp F, Guo W, Souto R, Pilch PF, Corkey BE, Hamilton JA: Rapid flip-flop of oleic acid across the plasma membrane of adipocytes. J Biol Chem 2003;278:7988-7995.

25 Hamilton JA: Fast flip-flop of cholesterol and fatty acids in membranes: implications for membrane transport proteins. Curr Opin Lipidol 2003;14:263-271.

-26 Hamilton JA: New insights into the roles of proteins and lipids in membrane transport of fatty acids. Prostaglandins Leukot Essent Fatty Acids 2007;77:355-361.

27 Phillips MC: Is ABCA1 a Lipid Transfer Protein? J Lipid Res 2018. pii: jlr.R082313. doi: 10.1194/jlr.R082313 [Epub ahead of print]. 